\title{
Rapid screening of the entire mitochondrial DNA for low-level heteroplasmic mutations
}

\author{
David Meierhofer ${ }^{1}$, Johannes A. Mayr ${ }^{1}$, Sabine Ebner, Wolfgang Sperl, Barbara Kofler* \\ Department of Paediatrics, Paracelsus Private Medical University Salzburg, Muellner Hauptstr. 48, A-5020 Salzburg, Austria
}

Received 11 March 2005; received in revised form 30 May 2005; accepted 2 June 2005

\begin{abstract}
Alterations of the mitochondrial DNA (mtDNA) are implicated in various pathological conditions. In this study, we used denaturing high performance liquid chromatography (DHPLC) as a method to rapidly screen the entire mtDNA for mutations. Overlapping DNA fragments, amplified by one single cycling protocol from frozen pre-formulated PCR mixes, were subjected to DHPLC analysis. Single DHPLC injections of fragments yielded straightforward interpretation of results with a detection limit down to $1 \% \mathrm{mtDNA}$ heteroplasmy. Furthermore, collection and re-amplification of low degree heteroduplex peak-fractions allowed sequence analysis of mtDNA mutations down to the detection limit of the DHPLC method. In order to demonstrate that the method has diagnostic value, we analyzed and confirmed known mtDNA mutations in patient samples. (C) 2005 Elsevier B.V. and Mitochondria Research Society. All rights reserved.
\end{abstract}

Keywords: DHPLC; MtDNA; Mutation; Heteroplasmy

\section{Introduction}

During the last decades, numerous mitochondrial point mutations have been identified in patients with diverse clinical phenotypes (Jaksch et al., 2001; Lenaz et al., 2004; Moslemi et al., 2004; Nishigaki et al., 2003). Although clinical manifestations of disorders that are related to mtDNA mutations are extremely variable, progress in genetic testing and identification

\footnotetext{
Abbreviations: DHPLC; denaturing high-performance liquid chromatography; mtDNA; mitochondrial DNA.

* Corresponding author. Tel.: + 436624482 4741; fax: + 43662 44824765.

E-mail address: b.kofler@salk.at (B. Kofler).

${ }^{1}$ Both authors contributed equally to this study.
}

of mitochondrial diseases has been achieved. A cell contains hundreds of mitochondria and thousands of copies of mtDNA molecules. Both normal and mutated mtDNA may coexist within a tissue, a condition known as heteroplasmy, whereas the presence of identical mtDNA molecules is called homoplasmy. Heteroplasmic pathogenic mutations can change over the course of time and exceed the pathogenic threshold in a particular tissue. Recent studies demonstrated that mtDNA mutations accumulate with increasing age (Jaksch et al., 2001; Murdock et al., 2000), that the level of heteroplasmy is associated with the age of onset and progression of chronic conditions, such as diabetic complications (Iwase et al., 2001) and that the decline in mitochondrial function can be due to 
the accumulation of mutations in mtDNA (Singh, 2004). Somatic homoplasmic and heteroplasmic changes have also been reported in a wide variety of cancers suggesting an influence on carcinogenesis (Singh, 2004; Yang et al., 2004; Zhu et al., 2005).

Denaturing high performance liquid chromatography (DHPLC), a method which separates heteroduplex and homoduplex DNA molecules on a stationary phase under partially denaturating conditions has already been shown to successfully detect unknown alterations in nuclear encoded genes (O'Donovan et al., 1998; Torrente et al., 2004; Xiao and Oefner, 2001) and the mtDNA (Conley et al., 2003; Danielson et al., 2003; LaBerge et al., 2003; Liu et al., 2002; van Den Bosch et al., 2000). DHPLC based methods are probably the most efficient approach for the detection of mutations and were shown to achieve highly reliable results (Torrente et al., 2004). In addition, detection and quantification of low-level heteroplasmy has been shown to be feasible by DHPLC (Conley et al., 2003). However, the methods to analyze the entire mtDNA have used either large amplicons in combination with a restriction digest or DHPLC analysis of single PCR fragments with indefinite resolution (Biggin et al., 2005; van Den Bosch et al., 2000). In addition, no simple method for sequence analysis of low-level heteroplasmy was provided.

Here, we describe a new DHPLC approach that allows and simplifies rapid screening of the entire $16.5 \mathrm{~kb}$ mtDNA genome, by using a combination of frozen pre-tested PCR mixes, a single PCR protocol for DNA amplification and DHPLC analysis. In addition, we developed a protocol to subsequently sequence low-level heteroplasmy.

\section{Materials and methods}

\subsection{Patients}

Samples from patients and family members were collected after informed consent was given.

\subsection{PCR amplification of the entire mitochondrial genome}

DNA of tissues, cells or blood leukocytes was extracted by proteinase $\mathrm{K}$ digestion followed by phenol/chloroform extraction. The whole human mtDNA was amplified by 48 overlapping DNA fragments ranging from 200 to $600 \mathrm{bp}$ (Table 1). The fragments overlapped by at least $40 \mathrm{bp}$. PCR mixtures contained $10 \times$ PCR buffer, $0.4 \mu \mathrm{M}$ of each primer, $120 \mu \mathrm{M}$ of each deoxynucleotide triphosphate and $0.45 \mathrm{U}$ of Optimase ${ }^{\circledR}$ DNA polymerase (Transgenomic San Jose, CA, USA). Pre-aliquoted reaction mixes $(30 \mu \mathrm{l})$ were stored at $-20{ }^{\circ} \mathrm{C}$. After thawing, $60 \mathrm{ng}$ of genomic DNA was added and all fragments were amplified with identical conditions: $95^{\circ} \mathrm{C}$ for $2 \mathrm{~min}, 35$ cycles of $95^{\circ} \mathrm{C}$ for $15 \mathrm{~s}, 57^{\circ} \mathrm{C}$ for $30 \mathrm{~s}$ and $72{ }^{\circ} \mathrm{C}$ for $1 \mathrm{~min}$, followed by a final extension at $72{ }^{\circ} \mathrm{C}$ for $5 \mathrm{~min}$. PCR products were visualized by gel electrophoresis on 2\% agarose gels stained with ethidium bromide. Pfu DNA polymerase (Promega, Madison, USA), Discoverase ${ }^{\mathrm{TM}}$ (Invitrogen, Santa Cruse, USA) and AmpliTaq Gold ${ }^{\circledR}$ DNA polymerase (Applied Biosystems, Warrington, UK) were used according to manufacturer's protocols.

\subsection{Mutation detection by DHPLC}

Denatured and re-annealed amplicons $(5 \mu \mathrm{l}$; heated at $98{ }^{\circ} \mathrm{C}$ for $2 \mathrm{~min}$ and cooled to $70{ }^{\circ} \mathrm{C}$ at a rate of $0.05^{\circ} \mathrm{C} / \mathrm{s}$ ) were directly injected into the dual plate WAVE 3500 apparatus equipped with a Hitachi D-7000 Interface, L-7100 Pump, L-7300 Oven, L-7400 UV Detector, DNASep ${ }^{\circledR}$ cartridge and the navigator $^{\mathrm{TM}}$ software version 1.5.4 (Transgenomic San Jose, CA, USA). The melting temperatures of the fragments and time shifts are given in Table 1. The gradient for the elution of the fragments (buffer A: 0.1 $\mathrm{M}$ triethylammonium acetate, B: $0.1 \mathrm{M}$ triethylammonium acetate, $25 \%$ acetonitrile) was created automatically with the navigator ${ }^{\mathrm{TM}}$ software.

Oven temperature for optimal heteroduplex separation under partial DNA denaturation was determined for each PCR fragment using the navigator software. Heteroplasmic peaks that were lower than the homoplasmic peak were manually collected and re-amplified.

\subsection{Introduction and analysis of artificial mutations}

PCR fragments of mtDNA regions containing an endogenous restriction site and an artificial mismatch 2-9 bp distant from the respective restriction site were 
Table 1

Primer sequences used to amplify the entire mtDNA in 48 overlapping fragments and DHPLC analysis temperatures as calculated by navigator software

\begin{tabular}{|c|c|c|c|c|c|c|c|}
\hline \multirow{2}{*}{$\frac{\text { Fragment }}{1}$} & \multirow{2}{*}{$\begin{array}{l}\text { Position } \\
108-638\end{array}$} & \multirow{2}{*}{$\begin{array}{l}\text { Sequence forward primer } \\
\text { AGCACCCTATGTCGCAGTATC }\end{array}$} & \multirow{2}{*}{$\begin{array}{l}\text { Sequence reverse primer } \\
\text { GGTGATGTGAGCCCGTCTAAAC }\end{array}$} & \multirow{2}{*}{$\begin{array}{l}\text { bp } \\
531\end{array}$} & \multicolumn{3}{|c|}{ Temperatures $\left({ }^{\circ} \mathrm{C}\right)$} \\
\hline & & & & & 58.3 & 59 & \\
\hline 2 & $548-964$ & CCAACCAAACCCCAAAGAC & GGGAGGGGGTGATCTAAAAC & 417 & 58.4 & 60 & \\
\hline $3^{\mathrm{a}}$ & $871-1250$ & $\begin{array}{l}\text { GCCCCGCCCCAGGGTTGGT- } \\
\text { CAATTTCGTGCC }\end{array}$ & GAGCAAGAGGTGGTGAGGTTG & 390 & 58.8 & & \\
\hline 4 & $1172-1612$ & CCTGGCGGTGCTTCATATCC & GCTACACTCTGGTTCGTCCAAG & 441 & 59.1 & & \\
\hline 5 & $1485-1950$ & GCCCGTCACCCTCCTCAAG & ACGGGTGTGCTCTTTTAGCTG & 466 & 57.9 & & \\
\hline 6 & $1883-2433$ & GGAGAGCCAAAGCTAAGACCC & GTGTTGGGTTGACAGTGAGGG & 551 & 56.6 & 57.8 & \\
\hline 7 & $2182-2722$ & GCAGCCACCAATTAAGAAAGCG & TCTCGTCTTGCTGTGTCATGC & 541 & 58 & 60.3 & \\
\hline 9 & $3079-3505$ & GGAGTAATCCAGGTCGGTT & TAGATGTGGCGGGTTTTAGG & 427 & 58 & 60.5 & \\
\hline 10 & $3438-3893$ & GCTACTACAACCCTTCGCTGAC & GTTCGGTTGGTCTCTGCTAGTG & 456 & 60 & & \\
\hline 11 & $3703-4203$ & CTGCGAGCAGTAGCCCAAAC & TGCTAGGGTGAGTGGTAGGAAG & 501 & 58 & 61.3 & \\
\hline 12 & $4183-4552$ & TTCCTACCACTCACCCTAGCA & AAAAATCAGTGCGAGCTTAGC & 370 & 56 & 59.2 & \\
\hline 13 & $4505-5003$ & CATCTTTGCAGGCACACTCATC & GATTTTGCGTAGCTGGGTTTGG & 499 & 58 & & \\
\hline 14 & $4955-5483$ & CATAGCAGGCAGTTGAGGTGG & AGGTAGGAGTAGCGTGGTAAGG & 529 & 56.3 & 58.7 & \\
\hline 15 & $5428-5926$ & CAАААСССАССССАТТССТСС & AATAGTCAACGGTCGGCGAAC & 499 & 57.7 & 58.6 & 60 \\
\hline 16 & $5861-6345$ & ACAGTCCAATGCTTCACTCAGC & AGATGGTTAGGTCTACGGAGGC & 485 & 59.7 & & \\
\hline 17 & $6266-6669$ & AGCAGGAACAGGTTGAACAGTC & GGGAGATTATTCCGAAGCCTGG & 404 & 60 & & \\
\hline 19 & $6747-7088$ & TTCCTAGGGTTTATCGTGTGAGC & GTGAATGAAGCCTCCTATGATGG & 342 & 60 & & \\
\hline 20 & $6954-7491$ & GGTGGCCTGACTGGCATTG & GTTGGCTTGAAACCAGCTTTGG & 538 & 58 & & \\
\hline 21 & $7403-7682$ & ACCCTACCACACATTCG & GGAAA ATGATTATGAGGGCG & 280 & 55.9 & 57.3 & \\
\hline 22 & $7612-8091$ & ACAAGACGCTACTTCCCCTATC & CCTAATGTGGGGACAGCTCATG & 480 & 57.5 & 59.5 & \\
\hline 23 & $8011-8560$ & AGTACTCCCGATTGAAGCCCC & GGGCAATGAATGAAGCGAACAG & 550 & 56.1 & 59 & \\
\hline 24 & $8466-8925$ & ACСТACСТCССТCACCAAAGC & TGTGCCTTGTGGTAAGAAGTGG & 460 & 57.8 & & \\
\hline 25 & 8854-9076 & GCGGGCACAGTGATTATAGG & TGGTTGATATTGCTAGGGTGGC & 223 & 60 & & \\
\hline 26 & $9001-9335$ & CGCCTAACCGCTAACATTACTG & GAGGAGCGTTATGGAGTGGAAG & 335 & 58.5 & 59.5 & \\
\hline 27 & $9271-9793$ & TCTCAGCCCTCCTAATGACCTC & GTTGAGCCGTAGATGCCGTC & 523 & 58 & 60 & \\
\hline 28 & 9742-9988 & CAGAGTACTTCGAGTCTCCCTTC & GACCCTCATCAATAGATGGAGAC & 247 & 59.9 & & \\
\hline 29 & $10,083-10,407$ & ATCAACACCCTCCTAGCCTTAC & CCAATTCGGCTCAGTCTAATCC & 325 & 57 & 60 & \\
\hline 30 & $10,279-10,634$ & CCCTACCATGAGCCCTACAAAC & TAAGAGGGAGTGGGTGTTGAGG & 356 & 55.5 & & \\
\hline 31 & $10,535-10,734$ & TCGCTCACACCTCATATCCTCC & AGTCTAGGCCATATGTGTTGGAG & 200 & 58.5 & 61 & \\
\hline 32 & $10,690-10,925$ & GCCTAGCCCTACTAGTCTCAATC & AGGTTGGGGAACAGCTAAATAGG & 236 & 57 & & \\
\hline 33 & $10,832-11,315$ & ATCAACACAACCACCCACAGC & GTTCTTGGGCAGTGAGAGTGAG & 484 & 59 & & \\
\hline 34 & $11,187-11,719$ & TGAACGCAGGCACATACTTCC & GCCGTGGGCGATTATGAGAATG & 533 & 58.6 & & \\
\hline 35 & $11,654-12,195$ & ACAGCCATTCTCATCCAAACCC & GGTCGTAAGCCTCTGTTGTCAG & 542 & 58 & 59 & \\
\hline 36 & $12,009-12,462$ & GCTCACTCACCCACCACAT & GGATGCGACAATGGATTTTA & 454 & 57.3 & & \\
\hline 39 & $13,249-13,785$ & TCCACTTCAAGTCAACTAGGAC & GGGGATTGTTGTTTGGAAGGG & 537 & 58.6 & & \\
\hline 40 & $13,708-14,070$ & GCAGCCGGAAGCCTATTCG & TGAGGTGATGATGGAGGTGGAG & 363 & 58.4 & & \\
\hline 41 & $13,930-14,371$ & ATCACACACCGCACAATCCC & ATTGGTGCTGTGGGTGAAAGAG & 442 & 57.3 & & \\
\hline
\end{tabular}




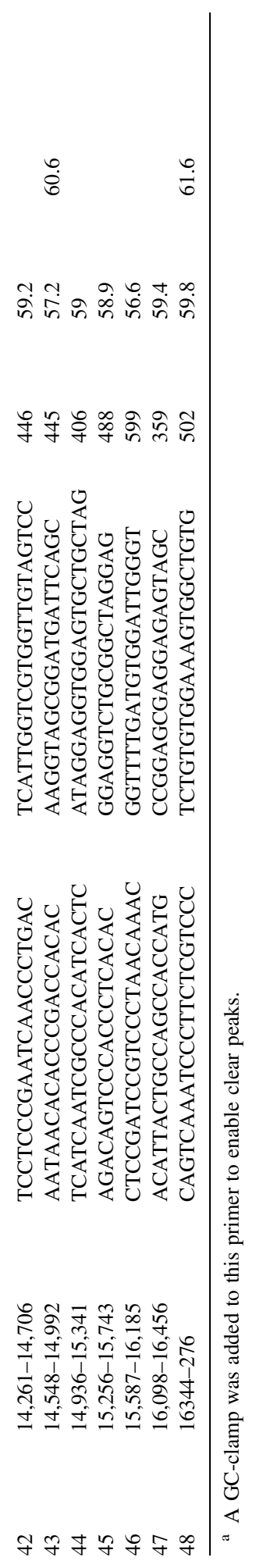

generated (Table 2). Since the mismatch position of the primers consisted of a 1:1 mixture of two bases (A/C, A/G, C/T; Table 2) mtDNA fragments with $50 \%$ heteroplasmy were amplified (Table 2). The affinity of the Optimase ${ }^{\circledR}$ DNA polymerase to the ends of PCR fragments prevents the restriction digest close to the ends of the amplicons. Therefore, a phenol-chloroform extraction of the PCR products was performed prior to restriction digest. Additives of the restriction digest reaction were separated from the DNA fragments via S400 columns (Amersham, Buckinghamshire, UK).

\subsection{Sequencing}

Not incorporated primers and nucleotides of the PCR reaction were removed by treatment with the EXOSAP-IT $^{\circledR}$ kit (USB Corporation, Ohio, USA). The PCR product $(2 \mu \mathrm{l})$ and EXOSAP-IT $(0.5 \mu \mathrm{l})$ were incubated at $37^{\circ} \mathrm{C}$ for $15 \mathrm{~min}$ and inactivated at $83^{\circ} \mathrm{C}$ for $15 \mathrm{~min}$ (total volume $4.5 \mu \mathrm{l}$ ).

The sequencing reaction $(10 \mu \mathrm{l})$ included: $0.5 \mu \mathrm{l}$ of PCR product, 5 pmol primer, $3 \mu$ l Quick Start Mix (10× sequencing reaction buffer, $10 \mu \mathrm{l}$ dNTPs, $20 \mu \mathrm{l}$ of each ddUTP, ddGTP, ddCTP, ddATP dye terminator and $10 \mu \mathrm{l}$ DNA polymerase; SNPkit\#390280, Beckman Coulter, Fullerton, CA). Cycle sequencing conditions were as follows: denaturation at $98^{\circ} \mathrm{C}$ for $40 \mathrm{~s}$, followed by 30 cycles of $96{ }^{\circ} \mathrm{C}$ for $20 \mathrm{~s}, 57^{\circ} \mathrm{C}$ for $20 \mathrm{~s}, 6{ }^{\circ} \mathrm{C}$ for $3 \mathrm{~min}$, all with a heating rate of $3{ }^{\circ} \mathrm{C} / \mathrm{s}$. Sequencing reactions were analysed on a Beckman Coulter CEQ ${ }^{\mathrm{TM}} 8000$ system (Fullerton, CA, USA). Exact positions of mutations and amino acid changes were defined with the mitoAnalyser tool, using the reference mtDNA sequence J01415.1.

\subsection{Determination of heteroplasmy of pathogenic mutations}

Restriction digests of the respective PCR fragments were carried out with the enzymes DdeI, HaeIII and MspI which cut specific the mutations $3302 \mathrm{G}, 3243 \mathrm{G}$ and $8993 \mathrm{G}$. The degree of heteroplasmy was detected by densitometry of ethidiumbromide stained agarose gels (Uziel et al., 1997; van den Bosch et al., 2004). 


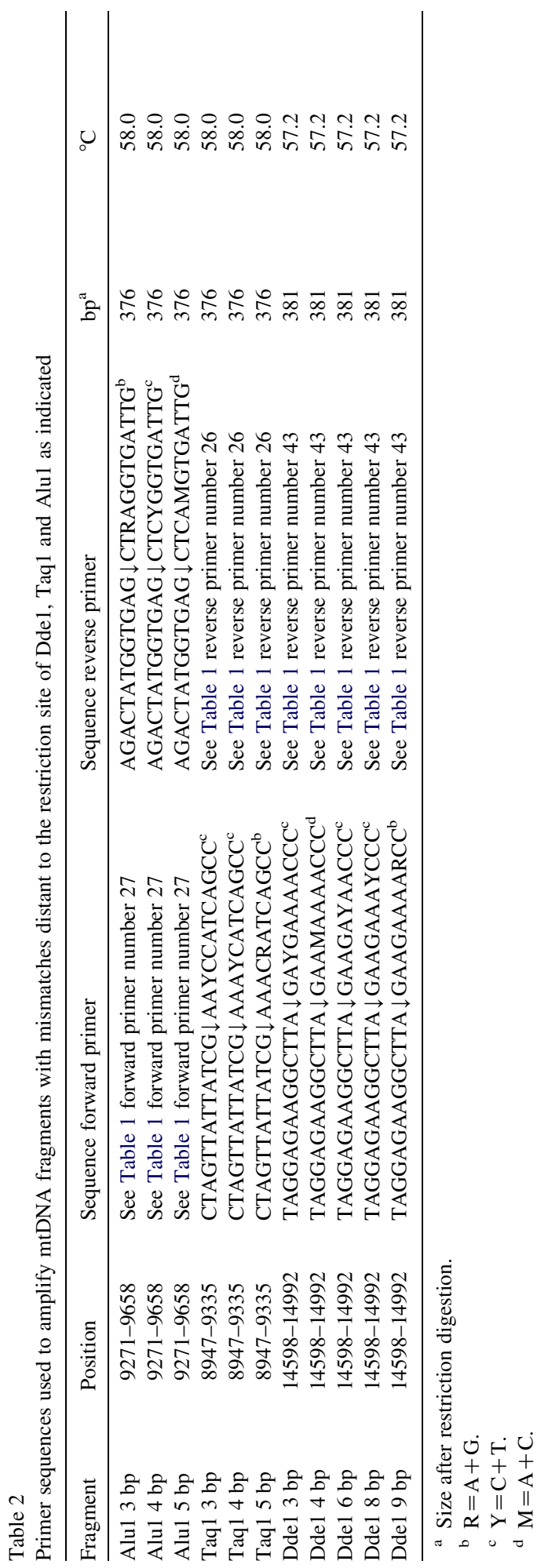

\section{Results}

\subsection{Amplification of the entire mtDNA}

PCR reactions were optimized to amplify the entire mtDNA in 48 overlapping fragments with one single cycling protocol (Table 1). The proof-reading Optimase ${ }^{\circledR}$ DNA polymerase, which is specifically designed for DHPLC analysis, was necessary to produce clear peaks with high amplitude (Fig. 1A,B). Other enzymes tested, like AmpliTaq Gold $^{\circledR}$ DNA polymerase and the proofreading $P f u$ and Discoverase $^{\mathrm{TM}}$ polymerases showed a wide spectrum of pre-peaks and shoulders in the DHPLC chromatogram leading to difficulties in detection of low-level heteroplasmies (Fig. 1C-H). In addition, the two latter enzymes need additives, which if not eliminated before DHPLC analysis, lead to early column decay.

Freezing of pre-formulated and pre-aliquoted PCR mixes did not change performance of amplification and DHPLC analysis but saved time and enhanced reproducibility (Fig. 2).

\subsection{Sensitivity of DHPLC analysis}

PCR amplicons of homoplasmic mtDNA displayed clear cut single homoduplex peaks in the DHPLC chromatogram. Heteroplasmic mutations lead to at least two peaks, the first one representing the heteroduplexes and the second one the homoduplexes (Figs. 3-6). Mixture of different quantities of two homoplasmic mtDNA variants revealed a detection limit of heteroplasmy down to $1 \%$, visible as a shoulder (Fig. 4). In cases of unclear low-level heteroplasmy, the heteroduplex peak was re-amplified. Presence of a mutation resulted in an equal mixture of heteroduplex and homoduplex peaks after DHPLC analysis (Fig. 5A,B).

Sensitivity of DHPLC analysis for mutations close to the end of a DNA fragment is an important issue if restriction digest of larger PCR products is used for mutation detection. By the use of degenerated primers we have introduced mismatches 2-9 bp distant from naturally occurring restriction sites leading to sticky or blunt ends of the DNA fragment (Table 2). All mutations in the fragments containing the Alu1 restriction site (blunt end) with mismatches in the primers at position three to five bases distant from 

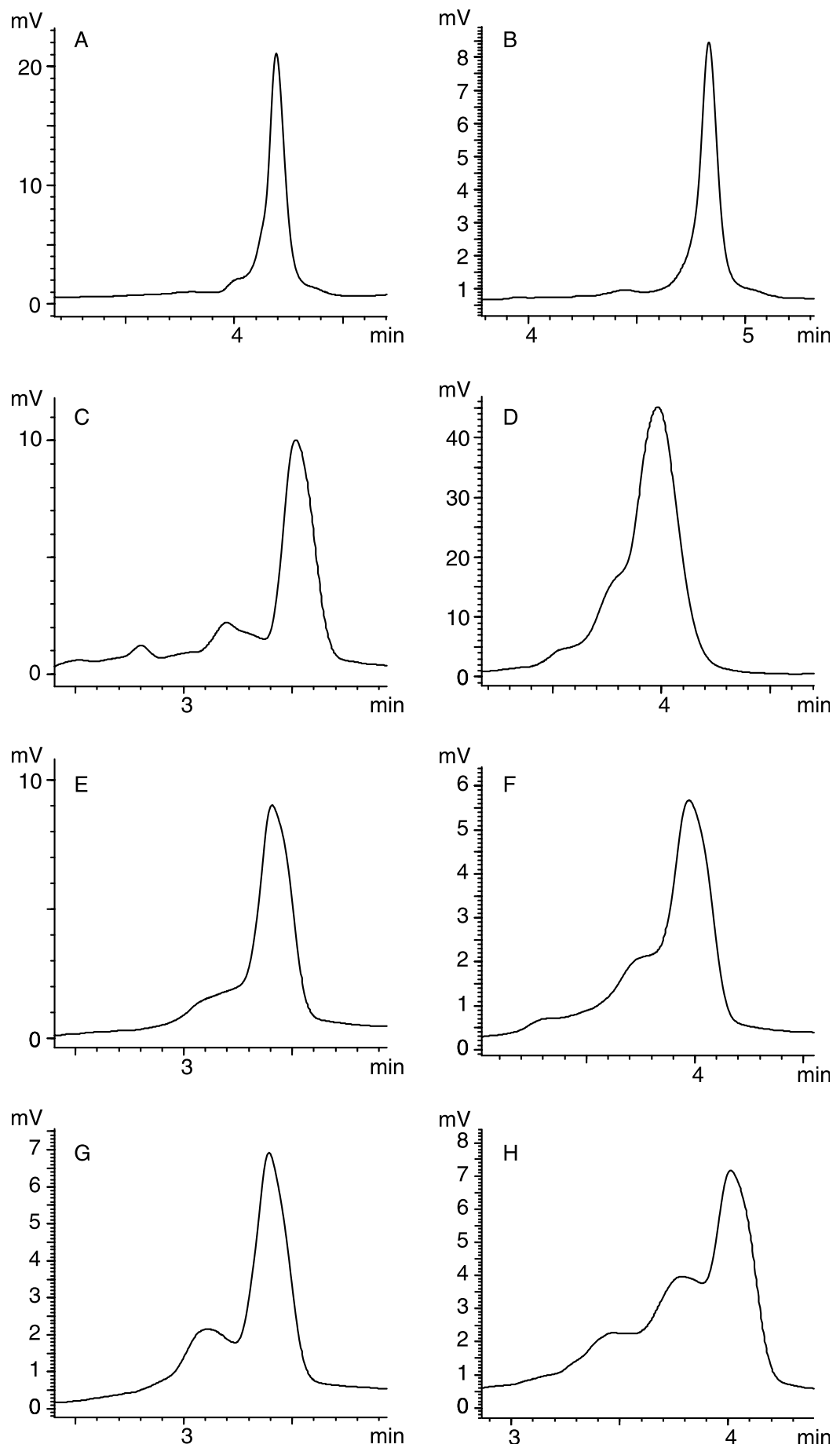

Fig. 1. DHPLC analysis of mtDNA fragment 7 (A,C,E,G) and fragment 8 (B,D,F,H) amplified with the following DNA polymerases: Optimase $^{\circledR}$ DNA polymerase (A,B), Discoverase ${ }^{\mathrm{TM}}(\mathrm{C}, \mathrm{D})$, Pfu DNA polymerase (E,F) and Ampli Taq Gold ${ }^{\circledR}$ DNA polymerase $(\mathrm{G}, \mathrm{H})$. 


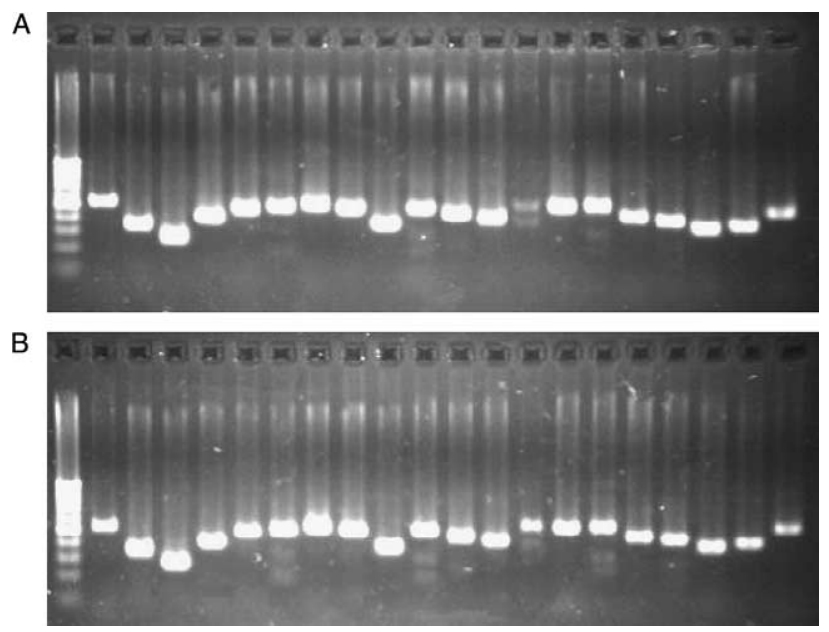

Fig. 2. Comparison of performance of fresh (A) and frozen (B) pre-aliquoted PCR reaction mixes for amplification of the first $20 \mathrm{mtDNA}$ fragments using a single cycling protocol and primers shown in Table 1.

the restriction site were identified correctly (Fig. 3A). The mutations in the Taq1 fragment (sticky end) were not detected clearly up until the fifth base pair from the restriction site (Fig. 3B). In the Dde1 fragment (sticky end), the mutation was undetectable from base pair 2-8 distant from the restriction site (Fig. 3C).

\subsection{Sequence analysis of heteroplasmic mtDNA}

Sequence analysis of heteroplasmy around 50\% gave clear results (Fig. 5D). As shown in other studies, low-level heteroplasmy was undetectable by direct sequencing (Fig. 5C). To allow sequence analysis of low-levels of polymorphic mtDNA, fractions of the small-sized heteroduplex peak were collected. After re-amplification the heteroplasmy increased to about $50 \%$, now allowing sequence analysis (Fig. 5A,B,D).

\subsection{Mutation analysis of patient samples}

To test the applicability of the protocol for detection of mtDNA variations by DHPLC established in this study, we analysed several samples from patients with proven pathogenic mtDNA mutations like A3302G, A3243G and T8993G. All tested mutations were detected correctly by our protocol (Fig. 6). A crude estimation of the degree of heteroplasmy $( \pm 10 \%)$ is possible by visual examination of the DHPLC chromatograms. In the samples investigated, the degree of heteroplasmy of DHPLC analysis corresponds well with the degree of heteroplasmy determined by restriction digest.

\section{Discussion}

In this study, a DHPLC-based protocol for the rapid detection of unknown variations of the entire human mtDNA was developed. To ensure clean homospecies peaks it was necessary to use the DHPLC optimized enzyme Optimase ${ }^{\circledR}$ DNA polymerase. This enzyme has the advantage that it does not need additives, which if not eliminated, would cause early column abrasion. A recent study also used DHPLC analysis of single PCR fragments to screen for mtDNA alterations (Biggin et al., 2005). Pfu DNA polymerase was used for mtDNA amplification, which created substantial pre-peaks in DHPLC analysis in about $20 \%$ of the fragments, a finding that is in agreement with our data. In general, pre-peaks in DHPLC analysis might be caused by the use of non-proofreading enzymes, suboptimal conditions for DNA polymerases as well as unwanted tailing of the PCR products. Secondary structures of certain PCR fragments might also lead to a proportion of incorrectly annealed fragments. Even in the course of the present study some fragments initially showed 

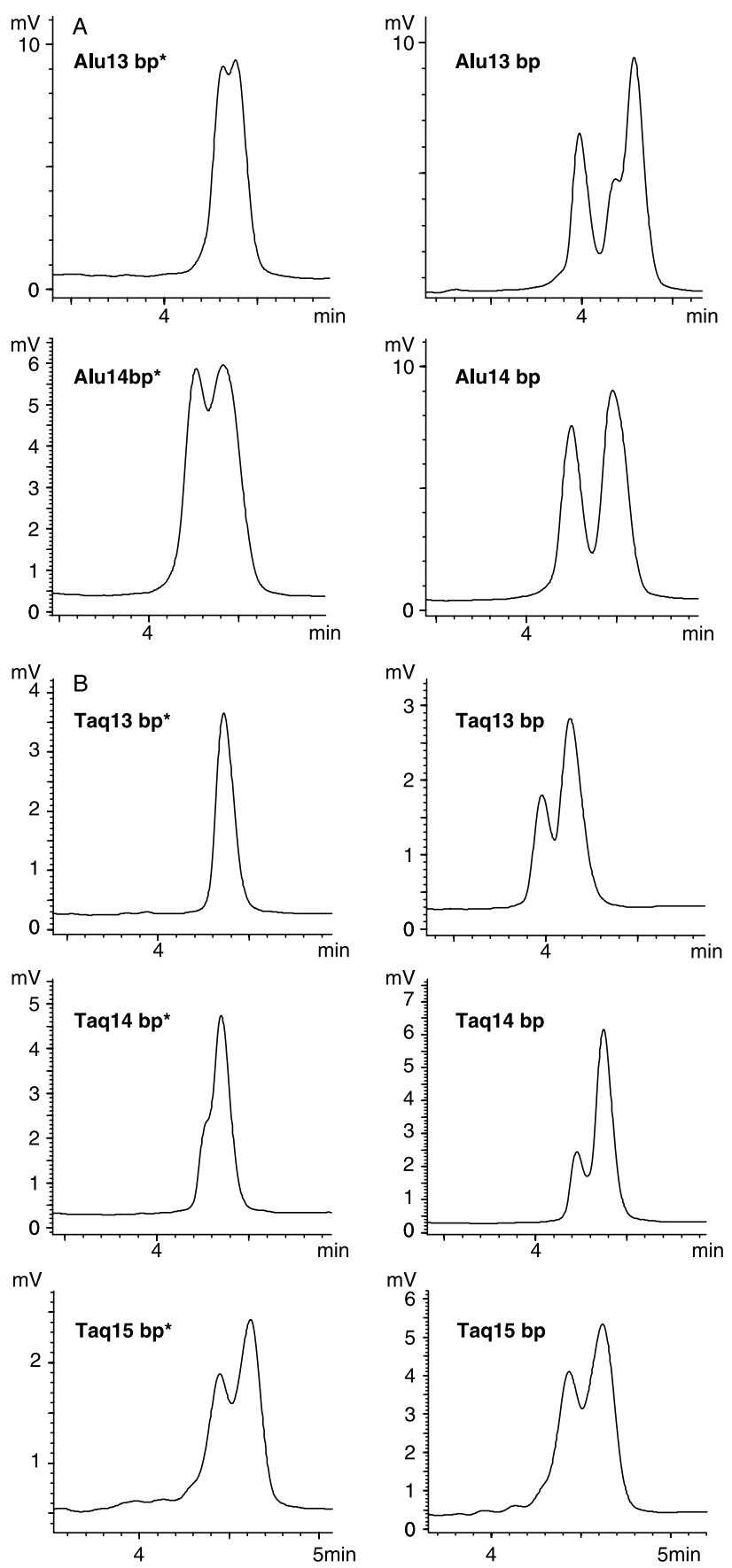

Fig. 3. Sensitivity of DHPLC analysis in detecting artificial heteroplasmy at certain distances from the end of a DNA fragment. Restriction sites and mutations were introduced into a PCR product with primers (Table 2) that contain the corresponding endogenous restriction site and mismatched bases at various distances to the restriction site (A, Alu1; B, Taq1; C, Dde1; as indicated in each figure). The distance of the heteroplasmic position to the end of fragment after restriction digest is indicated. DHPLC analysis was carried out with undigested and digested (*) PCR fragments. Since the heteroplasmy of the fragment was more than $10 \mathrm{bp}$ away from the end of the amplicon in the undigested DNA all mutations in the undigested PCR product were detected. 

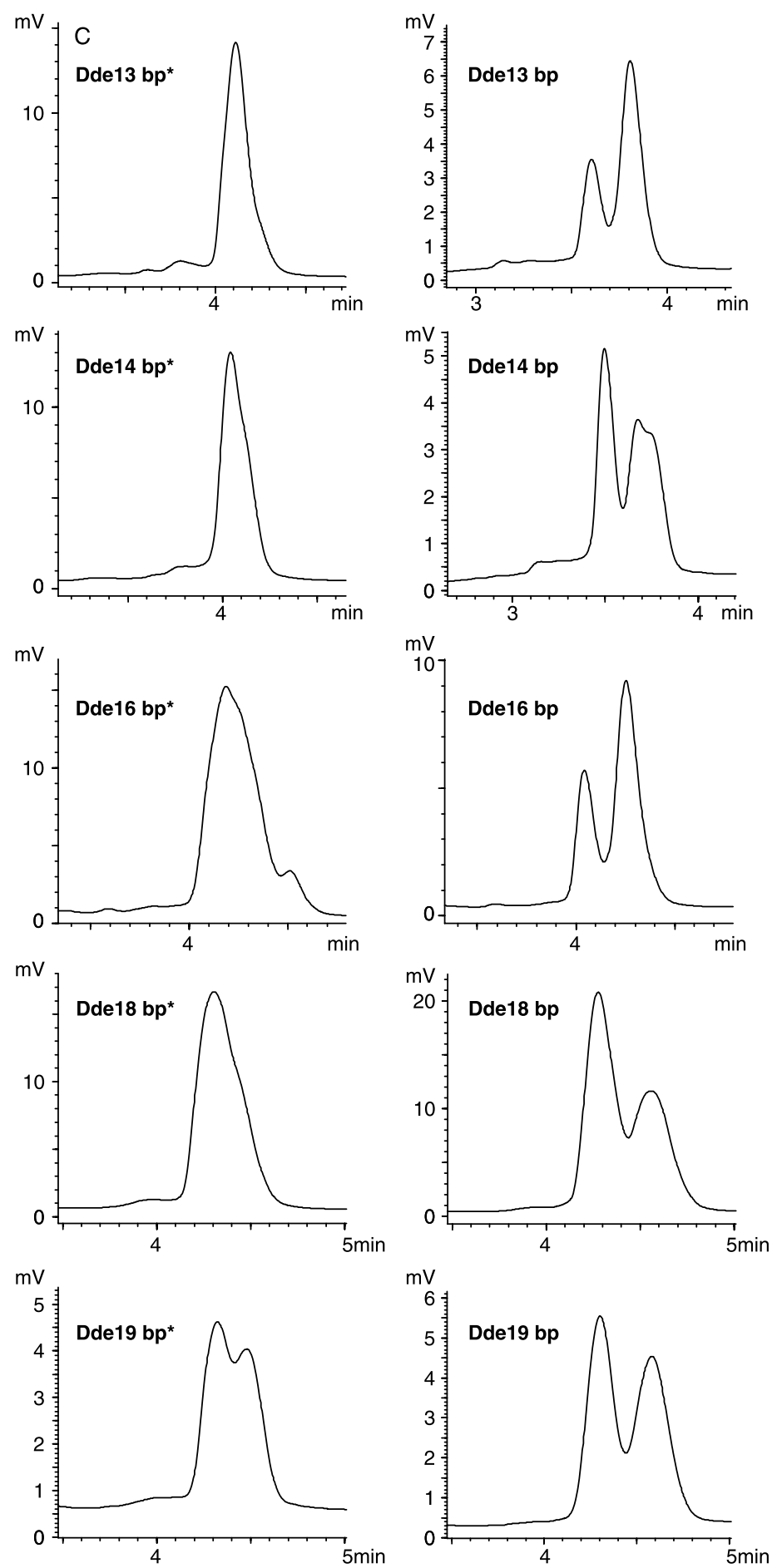

Fig. 3 (continued) 

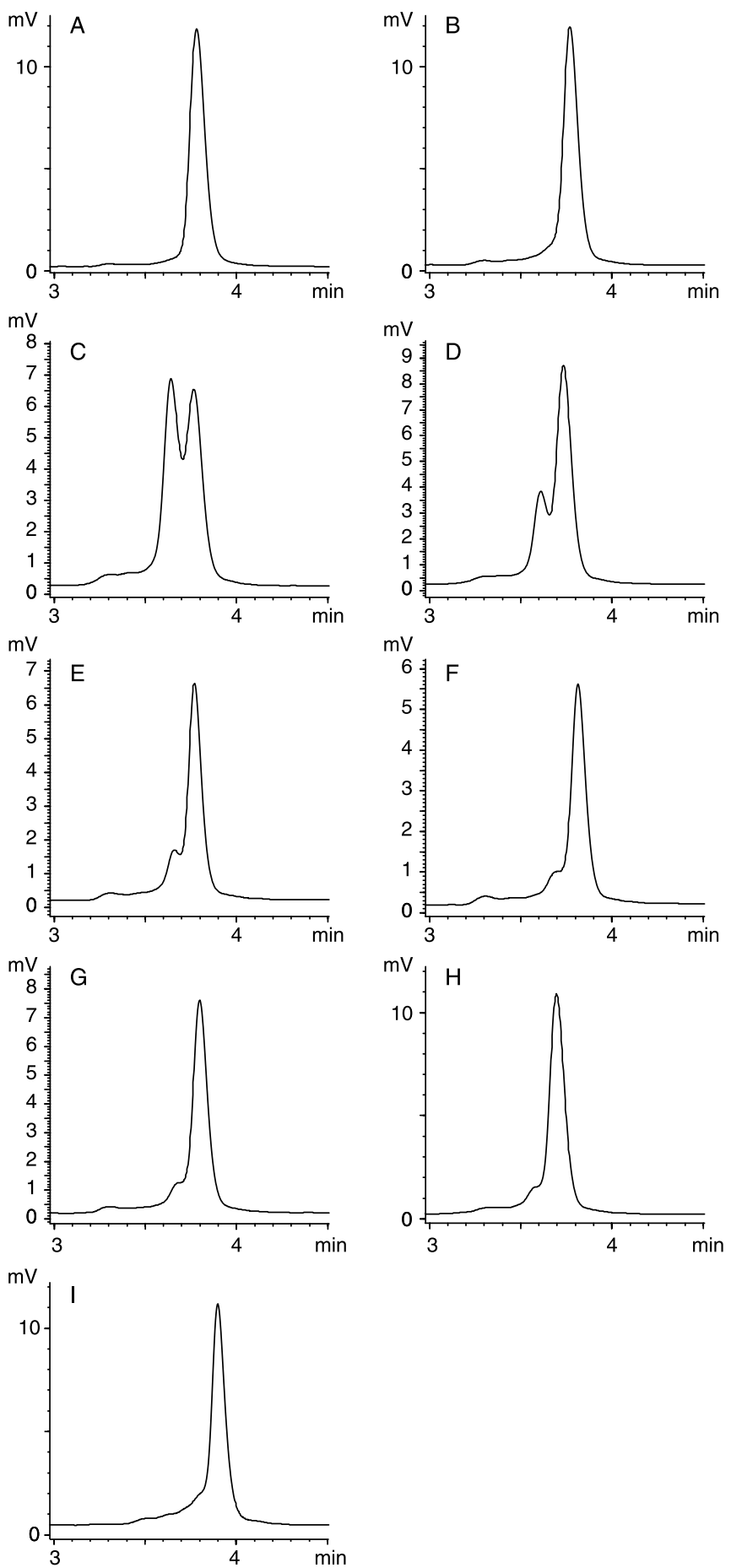

Fig. 4. Sensitivity of detection of heteroplasmy by DHPLC analysis of fragment 9. A, homoplasmic fragment with the A3305G mutation; B, same fragment of an unaffected control. Mixture of homoplasmic A3305G (I) and control (II) fragment: C, 50\% I and 50\% II; D, 90\% I and 10\% II; E, 95\% I and 5\% II; F, 97.5\% I and 2.5\% II; G, 99\% I and 1\% II; H, 99.5\% I and 0.5\% II; I, 99.9\% I and 0.1\% II. 
A

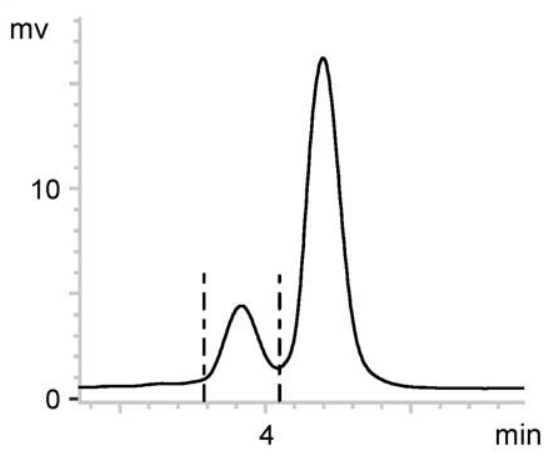

B

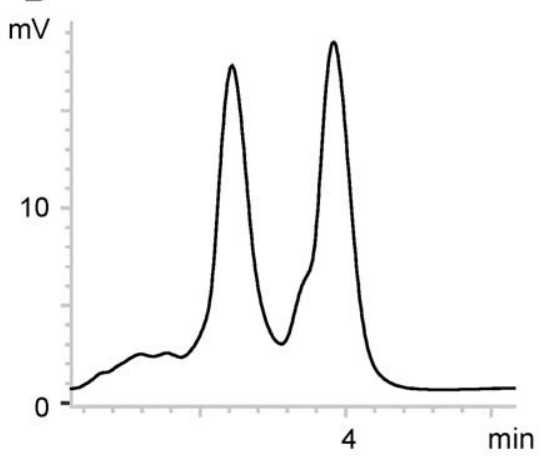

C
A C $\quad$ A
C A
$\begin{array}{llr}A & T \quad G \\ & & \end{array}$
G G
C $\underset{12010}{T} C$ A $C$ C

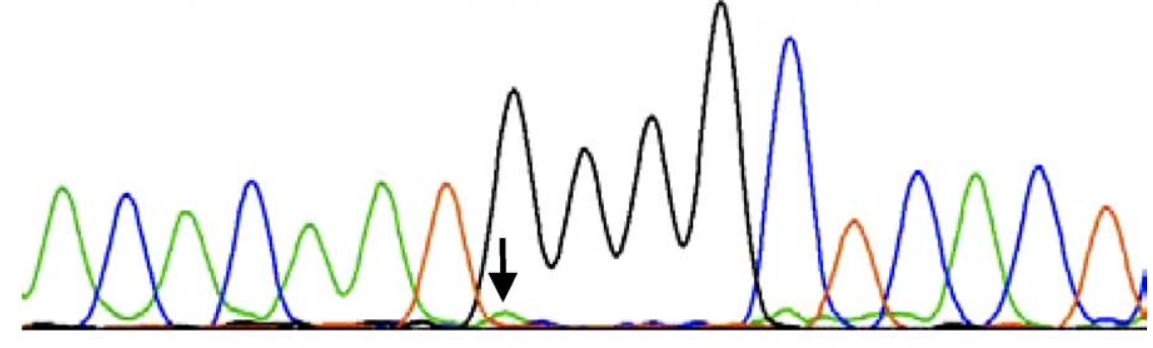

D
A $\quad \begin{array}{r}\text { A } A \\ 12000\end{array}$
C A
A $\quad \underset{12005}{G} G$
C $\underset{12010}{T} C$
A C T

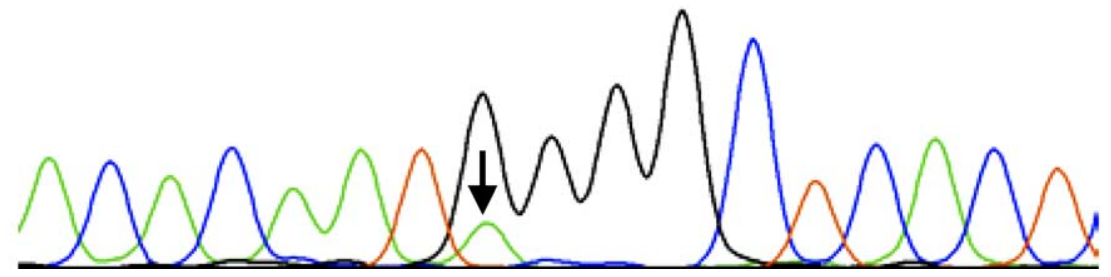

Fig. 5. A, DHPLC analysis of fragment 35 with a somatic heteroplasmy of less than $10 \%$. B, Re-amplification of the collected heteroplasmatic fraction results in one hetero-and one homoduplex peak of the same height. C, Direct sequence analysis of the PCR product gave no indication of a mtDNA variation. D, Sequence analysis of the re-amplified PCR fragment clearly shows the heteroplasmy at position 12005.

heteroduplex formation. Re-positioning of primers solved the problem.

van Den Bosch et al. (2000) analysed the entire mtDNA from 13 PCR fragments followed by restriction digest and multiplex DHPLC analysis at 5 different temperatures for each fragment. Since fragments lose the size-dependent separation at temperatures exceeding $53{ }^{\circ} \mathrm{C}$ (Xiao and Oefner, 2001), an interpretation of the DHPLC chromatograph is difficult, because peaks can overlap and low-level heteroplasmic peaks are lost in other peaks. In addition, polymorphisms in restriction sites further complicate the interpretation of the results.

We analysed artificially introduced mutations two to nine bp distant of a restriction site to determine the detection limit of the DHPLC analysis at the ends of digested fragments. We show for the first time, that detection of mutations close to the end of a PCR fragment is sequence and restriction enzyme specific. Mutations that are located up to $8 \mathrm{bp}$ away from 

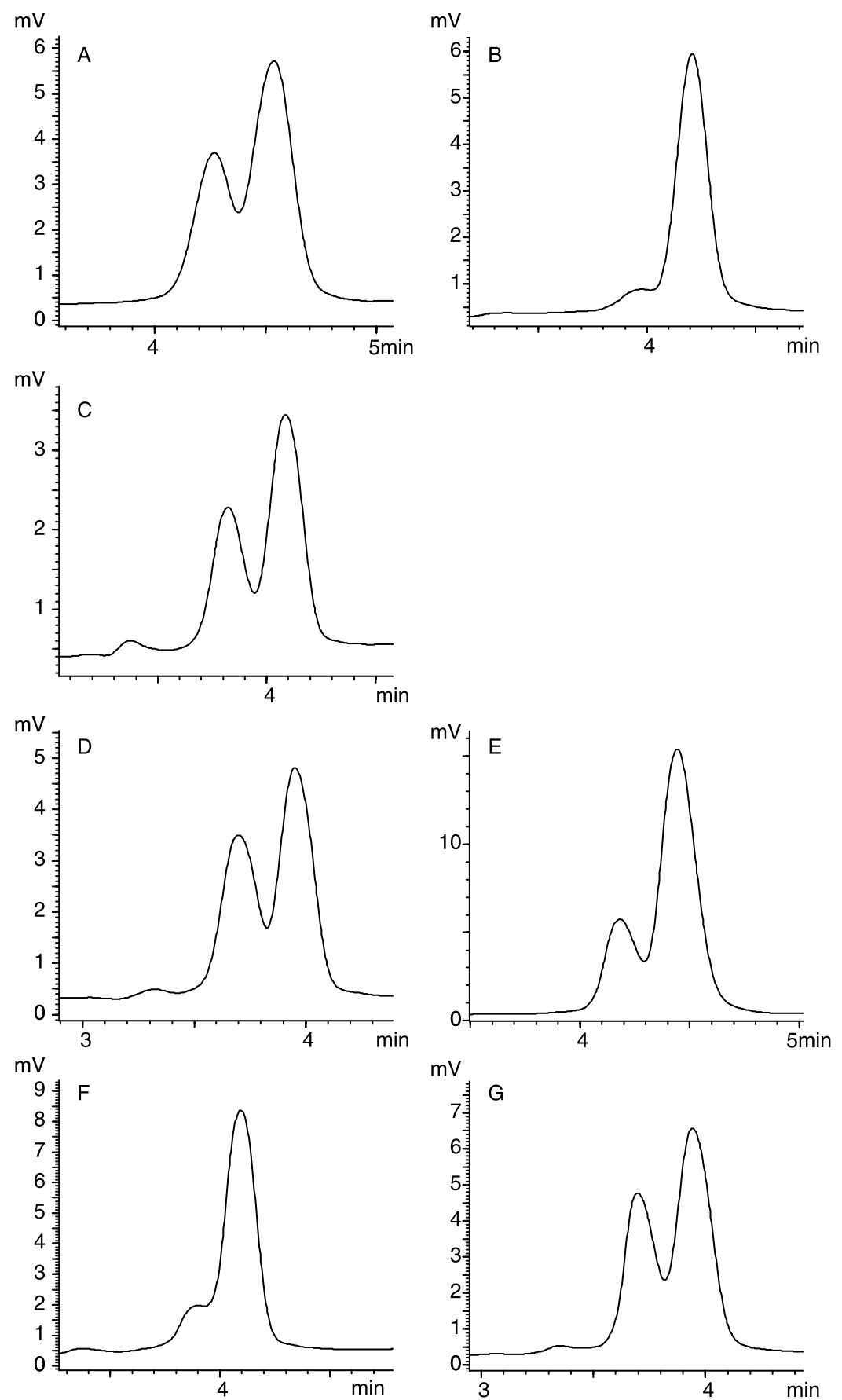

Fig. 6. DHPLC analysis of known mutations in the mtDNA of patients with different levels of heteroplasmy of mutations A3302G (A-C), A3243G (D-H) and T8993G (I-K). DHPLC analysis of A3302G mutation in fragment 9 of A, leukocytes of mother (35\%); B, muscle of son (96\%); C, leukocytes of son (60\%). DHPLC analysis of A3243G mutation in fragment 9 of D, leukocytes of mother (31\%); E, fibroblasts of son I $(89 \%)$; F, muscle of son I (92\%); G, leukocytes of son II (46\%); H, leukocytes of daughter (31\%). DHPLC analysis of T8993G mutation in fragment 25 of I: fibroblasts of patient (>99\%), J: unaffected control, K: mixture of I and J. The degree of heteroplasmy, as determined by densitometry of restriction digest of the PCR fragment, is given in brackets. 

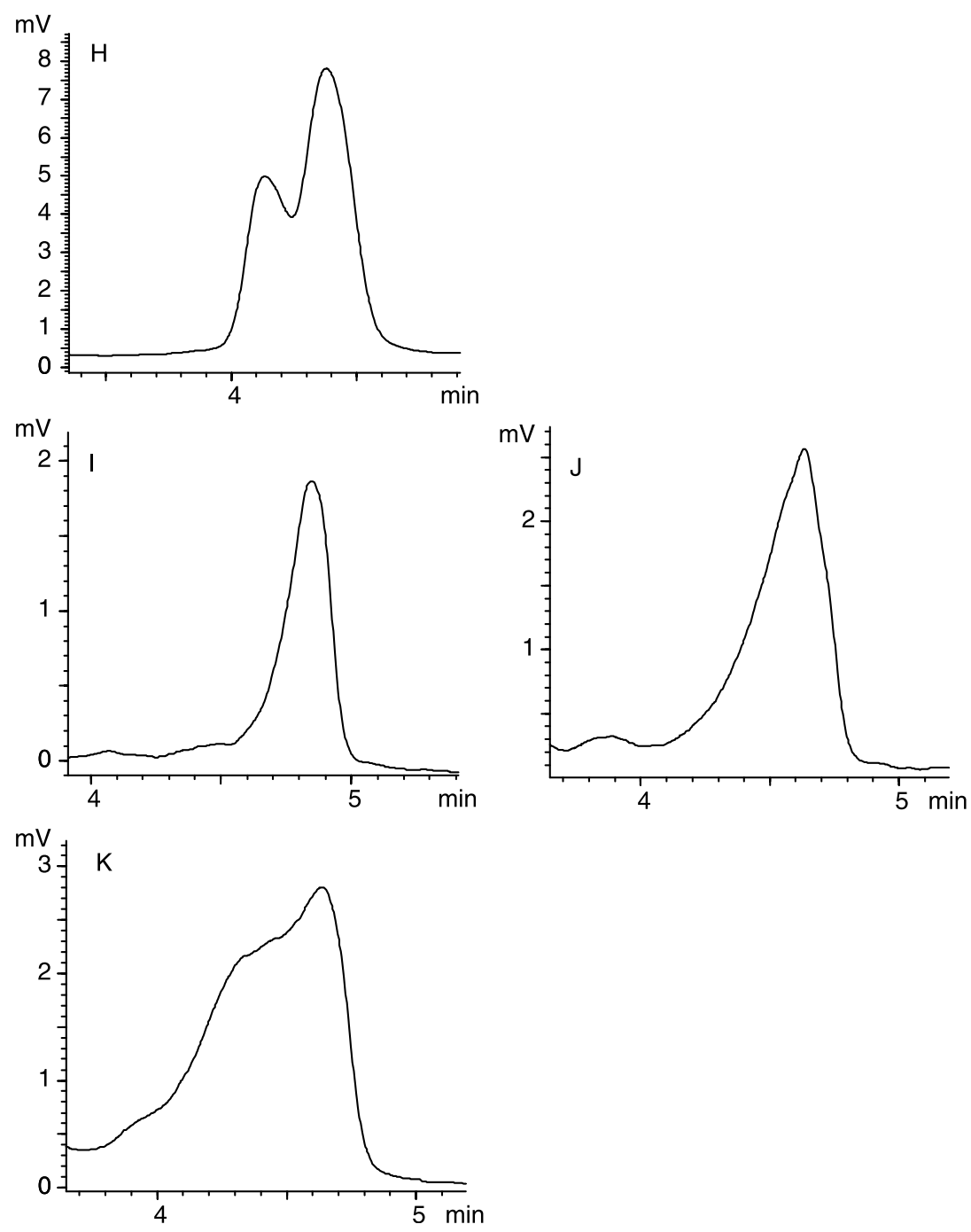

Fig. 6 (continued)

the end of the fragment can be missed. Depending on the fragment size this could account for $3-10 \%$ uncertainty of the analysed region.

Jones et al. (2001) sequenced DNA fragments of low-level mosaicism, which showed low heteroduplex peaks in DHPLC analysis. However, he was not able to detect the heteroplasmic mutation by direct sequence analysis. Finally, cloning of the fragments resulted in a few clones displaying the mutation. Here, we avoid time-consuming cloning of heteroduplex fragments for sequence analysis simply by collection and re-amplification of the heteroduplex peak. The re-amplification of low heteroplasmic peaks for sequence analysis could also be an important tool in diagnosis of mtDNA-related disorders. Since mtDNA mutations can segregate and accumulate in certain tissues, the level of heteroplasmy is frequently low in blood leukocytes compared to affected tissues. In cases of suspected pathological mtDNA mutations investigation of leukocytes, buccal swaps or urine 
sediment could be adequate for the detection of a pathological mutation. Another important application of the presented method will be the determination of a pathogenic mutation in the blood of maternal relatives. As a consequence appropriate genetic counselling of families with affected patients could be offered.

Pre-aliquoted PCR master mixes not only save time, but also lead to more reproducible results (Klausegger et al., 1999). Reactions for screening the entire mtDNA of one individual can be prepared within minutes simply by adding the template DNA. The mixes for screening one sample can be supplied in convenient 48 well plates. The possibility of semi-automated analysis of patient samples in 48 or 96 well plates within $24 \mathrm{~h}$ and comparable low cost make the proposed DHPLC method an ideal tool for the investigation of mtDNA variations.

In summary, we have developed a rapid protocol for the identification of variations of the entire mtDNA, which will allow high throughput screening for diseases with suspected involvement of mtDNA mutations.

\section{Acknowledgements}

The authors thank Alexandra Berger for stimulating discussions. This work was supported by the Österreichische Nationalbank (Jubiläumsfond Nr.10131), the Vereinigung zur Förderung Paediatrischer Forschung und Fortbildung Salzburg and the Children's Cancer Foundation Salzburg.

\section{References}

Biggin, A., Henke, R., Bennetts, B., Thorburn, D.R., Christodoulou, J., 2005. Mutation screening of the mitochondrial genome using denaturing high-performance liquid chromatography. Mol. Genet. Metab. 84, 61-74.

Conley, Y.P., Brockway, H., Beatty, M., Kerr, M.E., 2003. Qualitative and quantitative detection of mitochondrial heteroplasmy in cerebrospinal fluid using denaturing high-performance liquid chromatography. Brain Res. Protocol. 12, 99-103.

Danielson, P.B., Shelton, R.J., LaBerge, G.S., 2003. Clinical applications of denaturing high-performance liquid chromatography-based genotyping. Croat. Med. J. 44, 447-454.

Iwase, M., Gotoh, D., Urata, M., Kang, D., Hamasaki, N., Yoshinari, M., Fujishima, M., 2001. Clinical features of diabetic patients with $0.01-0.1 \%$ heteroplasmy A3243G mutation in leukocyte mitochondrial DNA. Diabetes Res. Clin. Pract. 54, 215-217.

Jaksch, M., Kleinle, S., Scharfe, C., Klopstock, T., Pongratz, D., Muller-Hocker, J., Gerbitz, K.D., Liechti-Gallati, S., Lochmuller, H., Horvath, R., 2001. Frequency of mitochondrial transfer RNA mutations and deletions in 225 patients presenting with respiratory chain deficiencies. J. Med. Genet. 38, 665-673.

Jones, A.C., Sampson, J.R., Cheadle, J.P., 2001. Low level mosaicism detectable by DHPLC but not by direct sequencing. Hum. Mutat. 17, 233-234.

Klausegger, A., Hell, M., Berger, A., Zinober, K., Baier, S., Jones, N., Sperl, W., Kofler, B., 1999. Gram type-specific broadrange PCR amplification for rapid detection of 62 pathogenic bacteria. J. Clin. Microbiol. 37, 464-466.

LaBerge, G.S., Shelton, R.J., Danielson, P.B., 2003. Forensic utility of mitochondrial DNA analysis based on denaturing highperformance liquid chromatography. Croat. Med. J. 44, 281-288.

Lenaz, G., Baracca, A., Carelli, V., D’Aurelio, M., Sgarbi, G., Solaini, G., 2004. Bioenergetics of mitochondrial diseases associated with mtDNA mutations. Biochim. Biophys. Acta. 1658, 89-94.

Liu, M.R., Pan, K.F., Li, Z.F., Wang, Y., Deng, D.J., Zhang, L., Lu, Y.Y., 2002. Rapid screening mitochondrial DNA mutation by using denaturing high-performance liquid chromatography. World J. Gastroenterol. 8, 426-430.

MitoAnalyzer, 2000. MitoAnalyzer. National Institute of Standards and Technology, Gaithersburg, MD, USA. http://www.cstl.nist. gov/biotech/strbase/mitoanalyzer.html.

Moslemi, A.R., Lindberg, C., Toft, J., Holme, E., Kollberg, G., Oldfors, A., 2004. A novel mutation in the mitochondrial tRNA(Phe) gene associated with mitochondrial myopathy. Neuromuscul. Disord. 14, 46-50.

Murdock, D.G., Christacos, N.C., Wallace, D.C., 2000. The agerelated accumulation of a mitochondrial DNA control region mutation in muscle, but not brain, detected by a sensitive PNAdirected PCR clamping based method. Nucleic Acids Res. 28, 4350-4355.

Nishigaki, Y., Tadesse, S., Bonilla, E., Shungu, D., Hersh, S., Keats, B.J., Berlin, C.I., Goldberg, M.F., Vockley, J., DiMauro, S., Hirano, M., 2003. A novel mitochondrial tRNA(Leu(UUR)) mutation in a patient with features of MERRF and Kearns-Sayre syndrome. Neuromuscul. Disord. 13, 334-340.

O’Donovan, M.C., Oefner, P.J., Roberts, S.C., Austin, J., Hoogendoorn, B., Guy, C., Speight, G., Upadhyaya, M., Sommer, S.S., McGuffin, P., 1998. Blind analysis of denaturing high-performance liquid chromatography as a tool for mutation detection. Genomics 52, 44-49.

Singh, K.K., 2004. Mitochondrial dysfunction is a common phenotype in aging and cancer. Ann. NY Acad. Sci. 1019, 260-264.

Torrente, I., Arturi, F., D'Aloiso, L., Colosimo, A., De Luca, A., Ferretti, E., Russo, D., Chiefari, E., Scarpelli, D., Bisceglia, M., Dallapiccola, B., Filetti, S., 2004. Evaluation of a DHPLC-based 
assay for rapid detection of RET germline mutations in Italian patients with medullary thyroid carcinoma. J. Endocrinol. Invest. 27, 111-116.

Uziel, G., Moroni, I., Lamantea, E., Fratta, G.M., Ciceri, E., Carrara, F., Zeviani, M., 1997. Mitochondrial disease associated with the T8993G mutation of the mitochondrial ATPase 6 gene: a clinical, biochemical, and molecular study in six families. J. Neurol. Neurosurg. Psychiatry 63, 16-22.

van Den Bosch, B.J., de Coo, R.F., Scholte, H.R., Nijland, J.G., van Den Bogaard, R., de Visser, M., de Die-Smulders, C.E., Smeets, H.J., 2000. Mutation analysis of the entire mitochondrial genome using denaturing high performance liquid chromatography. Nucleic Acids Res. 28, E89. van den Bosch, B.J., de Coo, I.F., Hendrickx, A.T., Busch, H.F., de Jong, G., Scholte, H.R., Smeets, H.J., 2004. Increased risk for cardiorespiratory failure associated with the A3302G mutation in the mitochondrial DNA encoded tRNALeu(UUR) gene. Neuromuscul. Disord. 14, 683-688.

Xiao, W., Oefner, P.J., 2001. Denaturing high-performance liquid chromatography: a review. Hum. Mutat. 17, 439-474.

Yang, J.H., Lee, H.C., Chung, J.G., Wei, Y.H., 2004. Mitochondrial DNA mutations in light-associated skin tumors. Anticancer Res. 24, 1753-1758.

Zhu, W., Qin, W., Bradley, P., Wessel, A., Puckett, C.L., Sauter, E.R., 2005. Mitochondrial DNA mutations in breast cancer tissue and in matched nipple aspirate fluid. Carcinogenesis 26, 145-152. 